happen, I mention a boy of Io who had made an excellent adjustment to his complete paraplegia below TII and his father came, bitterly complaining that his boy-an intelligent boy-was put into a school for disabled children. I got in touch with the medical authorities and in those years they were not very helpful at all. Had there not been an understanding headmaster who took him into his ordinary school this boy would have been kept in that school for the disabled. He became an excellent pupil and won first a scholarship to Reading University in mathematics and from there he won a scholarship in mathematics to Trinity College, Cambridge! After his exam he became a lecturer at Nottingham University in mathematics. He is now-happily married-with a fellowship at Princeton University in the U.S.A. If this boy had been kept in a school for disabled children he might be perhaps a second class clerk somewhere in an office.

Dr. D. BuRke (Australia). Just a few brief points-I obviously didn't have time in this paper to discuss the late problems of progress in these children. This is another subject in itself so this was not touched upon. My main reason for presenting this paper was to ask questions. What is the pathology in these lesions? Just replying to a couple of specific points that were raised: to Dr. Young, no, we do not use myography, we do not have it. We have willing workers but we don't have much equipment. Lap belts, Dr. Hallin, 98 or 99 per cent. of our patients from motor car accidents were not wearing seat belts-the seven we have now had who were wearing seat belts at the time of their accident only two were lap and sash, all the rest were lap belts. I don't think there is enough evidence in favour of seat belts. And, Sir Ludwig-the one child we have in a handicapped school is a little fat Greek boy who is not coping terribly well with his paraplegia, thanks to his parents who are not coping very well, and for these reasons and physical reasons-we need to continue physiotherapy-he needs a special school, temporarily, we hope, for a year or two.

\title{
THE RESULTS OF LAMINECTOMY IN PATIENTS WITH INCOMPLETE SPINAL CORD INJURIES
}

\author{
By T. H. Morgan, M.D., George W. Wharton, M.D., and George N. Austin, M.D. \\ Division of Orthopaedic Surgery, University of Maryland Hospital, \\ Baltimore, Maryland 2I20I
}

THE orthopaedic and neurosurgical literature contain clear and definite indications for laminectomy. Nevertheless, laminectomy continues to be a routine part of the early management of spinal cord injuries, both in patients with complete and incomplete lesions, in many areas of the United States. Patients continue to arrive at rehabilitation centres with records from acute hospitals which indicate that, although specific benefits could not be anticipated, exploratory laminectomies were performed to evaluate the condition of the spinal cord. The implicit suggestion is that no harm will result from this procedure.

This study is based on a review of 230 patients with traumatic spinal cord injuries admitted to the Montebello State Rehabilitation Hospital, Baltimore, Maryland, from I953 through 1968. Seventy of the 230 patients had well-documented incomplete spinal cord injuries. The observation that significant neurological deterioration occurred in a number of patients following laminectomy suggested that a review of these patients might further clarify the role of laminectomy in the management of the acute spinal cord injury. 


\section{REVIEW OF THE LITERATURE}

There has been controversy surrounding the correct management of the spinal cord injury in the literature of the United States and Europe for decades. Before the establishment of spinal cord injury centres after World War II, few physicians treated large numbers of these injuries, and the high mortality permitted only limited follow-ups, at best. The publication of clinical impressions based on limited experience is probably responsible for many of the practices which persist today.

Guttmann (1949) was among the first to clearly recommend avoidance of laminectomy in patients with acute spinal cord injuries. His position was that rehabilitation should take precedence over operative intervention. He also noted that delayed laminectomy was rarely beneficial and carried the risk of additional unnecessary complications.

In the early I960s, several large series of patients were reviewed and reports evaluating various forms of management resulted. Taylor and Gleave (I962) set forth the indications for laminectomy and considered that open wounds, radiological evidence of bone fragments within the spinal canal, or the presence of an irreducible fracture-dislocation justified the procedure of laminectomy.

Cloward (1963), in a lengthy study published in 1963, emphasised that decompression laminectomy was rarely indicated but that stabilisation of the spine was of the utmost importance. Carey (1965) and Harris (1965-66) re-emphasised the limited indications for decompression laminectomy, and Carey specifically indicated that neurological deterioration after laminectomy was a significant risk.

Walker (1964) discussed the indications for laminectomy and stated, 'The majority of patients with closed cervical cord injuries, do better with skeletal traction than with decompressive operation because the mildly swollen more discolored cord is easily damaged by manipulative operation'. Walker also acknowledged the need for adequate surgical stabilisation. In 1966, Munro (1965-66) reviewed the need for open reduction when necessary to secure proper realignment of the spinal canal, and Benassy et al. (1967) published a series of 600 paraplegic and quadriplegic patients showing that laminectomy was not helpful in most patients with thoracic and lumbar spine injuries.

The vascular changes in spinal cord injuries have recently been studied in animals. White et al. (1969) have documented the acute tissue damage associated with permanent paraplegia produced by direct impact on the spinal cord in monkeys. These authors have repeatedly emphasised that in experimental animals the reversible changes are present only up to four hours after injury and that 'the initiation of spinal cord cooling, six to eight hours after injury, fails to alter significantly the morphological appearance of the traumatized cord'. There is no evidence that reversible damage which would respond to hypothermic treatment is present for any greater period than four hours in man.

\section{MATERIAL AND STATISTICS}

Two hundred and thirty spinal cord injured patients admitted to the Montebello State Rehabilitation Hospital over a I5-year period were studied. One hundred and twenty-eight of the patients suffered complete transections of the 
spinal cord at the time of their original injury. Seventy of the remaining patients had well-documented incomplete spinal cord injuries. The remaining 32 patients were inadequately documented for inclusion in this series.

TABLE I

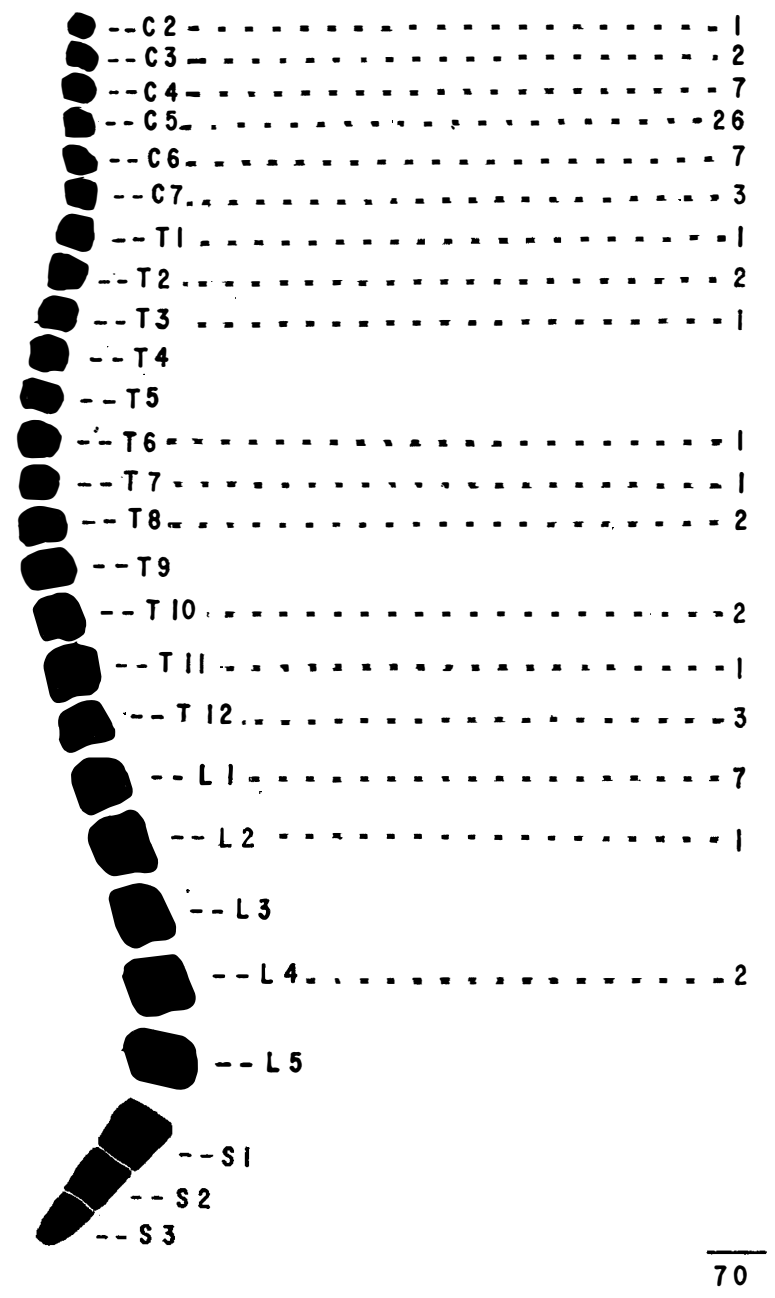

\section{LEVEL OF VERTEBRAL LESIONS}

The 70 patients with incomplete lesions were selected for this study because, in 32 of these patients, the loss of function following laminectomy is documented with tragic clarity. From our overall review, it was apparent that no patient with a complete spinal cord injury at any level benefited from exploratory or decompressive laminectomy.

Table I shows the levels of incomplete lesions included in this series. The 
large number of cervical spine injuries reflects the greater frequency with which these injuries result in a need for the series of a rehabilitation facility. Patients had vertebral fractures from the second cervical through the fourth lumbar levels.

TABLE II

Etiology of Injuries

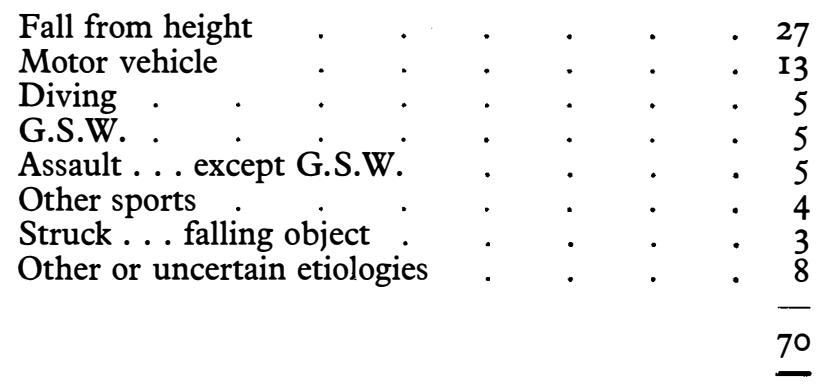

TABLE III

Parameters reviewed and Evaluated

I. Age of patients

2. Sex of patients

3. Laminectomy procedures

4. Surgical stabilisations

5. Time of first surgery after injury

6. Reduction of fracture dislocations

\section{TABLE IV}

Comparison of Patients treated with and without Laminectomy

After laminectomy

42 Patients

\begin{tabular}{r} 
No. Pa \\
14 \\
22 \\
6 \\
\hline 42 \\
29 \\
27
\end{tabular}

Without laminectomy 28 Patients

No. Patients

\begin{aligned}$\% & \\ 54 &$ improved \\ 0 & worse \\ 46 & no change \\ \hline I00 & \\ 50 & required \\ & stabilisation \\ 4 & not reduced \end{aligned}

Table II illustrates the aetiology of the injuries. Falls from a height and motor vehicle accidents continue to be the leading causes of these injuries. A rising incidence of spinal cord injuries secondary to gunshot wounds has been noted with a seven-fold increase since 1965. Regrettably, few of these injuries result in incomplete neurological lesions. 
Table III lists the major parameters which were utilised in assessing the role of laminectomy in the treatment of patients with incomplete spinal cord injuries. The patients were reviewed with regard to their level of injury, aetiology of injury,

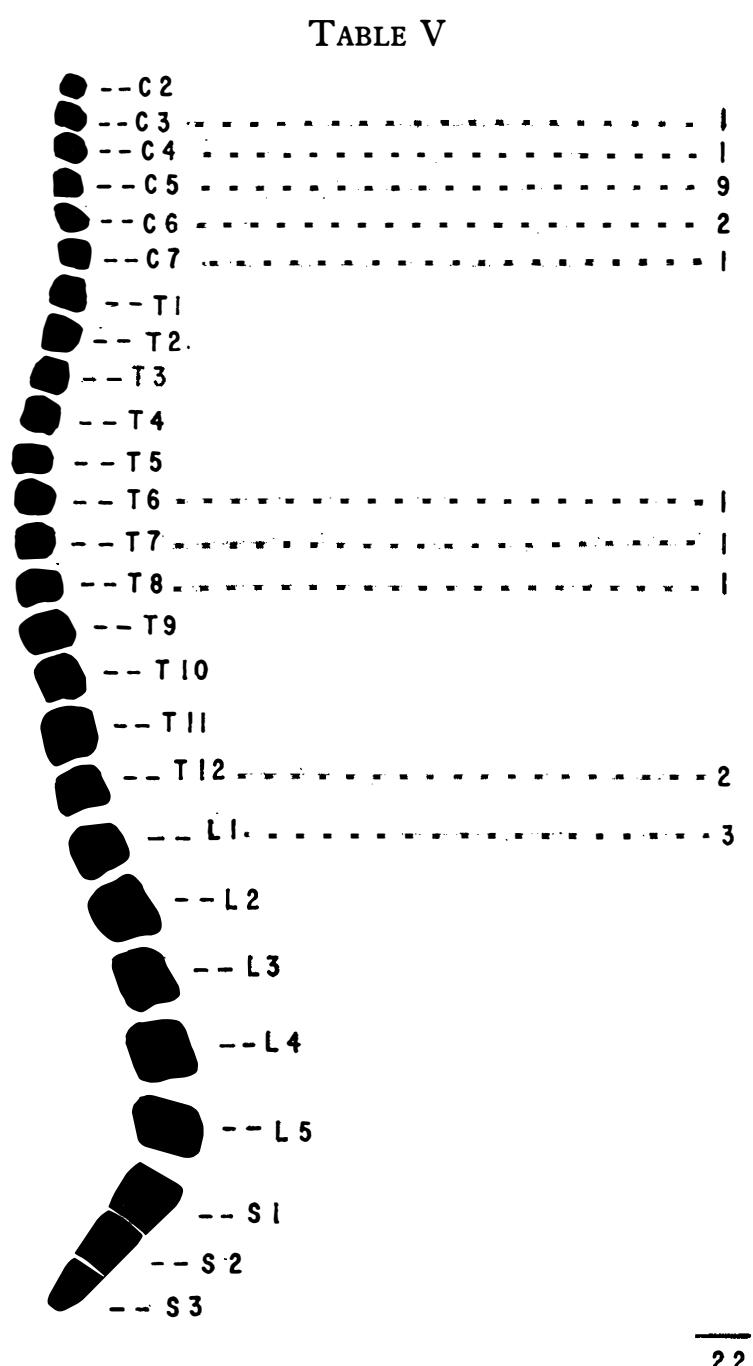

LEVEL OF VERTEBRAL LESIONS

IN

\section{PATIENTS DETERIORATING AFTER LAMINECTOMY}

type of operative procedure, and the time elapsed from injury until the first operative procedure was performed. An attempt was also made to evaluate stability. Finally, current roentgenograms were examined to evaluate the condition of the spine with regard to the presence or absence of adequate reduction and stability. 
Table IV summarises the findings in the 70 patients with incomplete spinal cord injuries. Laminectomies were performed in 42 of the 70 patients. Only 14 patients ( 33 per cent.) with incomplete lesions improved neurologically after laminectomy. Twenty-two patients (52 per cent.) lost neurological function following this surgical procedure. In contrast, without laminectomy, I 5 of the 28 patients (54 per cent.) improved and no neurological deterioration occurred in this group of patients.

Fourteen of the 22 patients who lost neurological function had cervical cord injuries. All were severely disabled following laminectomy and ten developed complete quadriplegia. Table $\mathrm{V}$ indicates the levels of lesions treated by laminectomy with loss of neurological function post-operatively. Four of the remaining nine patients suffered permanent loss of bowel and bladder control after laminectomy in the mid-thoracic or upper lumbar level.

VABLE VI

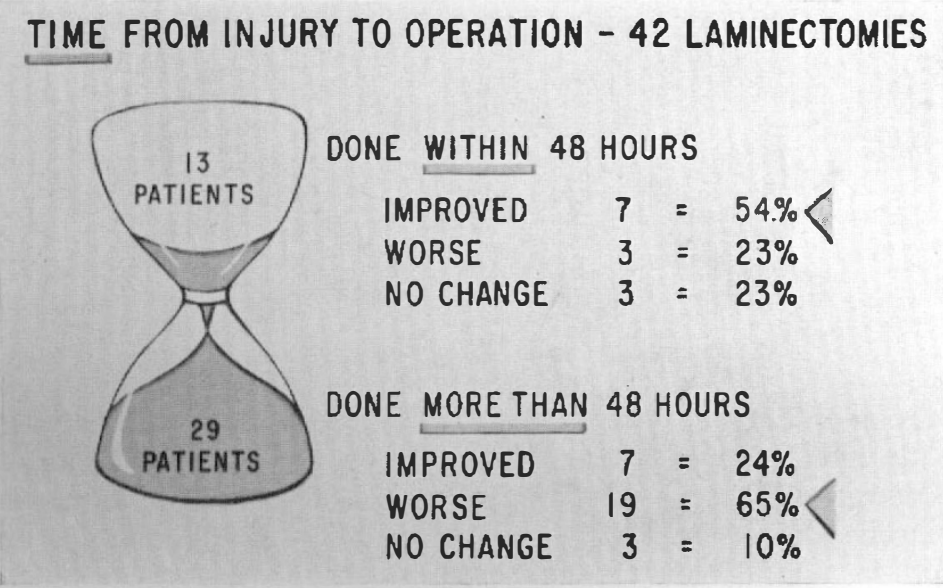

Current opinions expressed in the literature suggest that delayed laminectomy may be carried out with less risk than that associated with the procedure in the acute injury. Our experience contradicts this belief. Delayed surgical intervention by laminectomy appeared to be correlated with an increased incidence of poor results. Table VI shows a comparison of results obtained when patients had laminectomies performed within 48 hours after injury and more than 48 hours after injury. Thirteen patients were operated on within 48 hours and of these, seven improved while three deteriorated post-operatively. In contrast, those patients operated upon more than 48 hours after injury were 29 in all and only seven patients improved, whereas I9 patients lost neurological function. The authors are unable to explain the deterioration of 65 per cent. of patients having laminectomies more than 48 hours after injury. It would seem reasonable to assume that further vascular compromise associated with the trauma of surgery could be responsible for the further deterioration in this group of patients.

One of the more commonly accepted indications for laminectomy is to reduce a dislocation which cannot be reduced by closed methods. Reduction and 
acceptable alignment of the spine was not achieved in 28 (40 per cent.) of the patients with incomplete lesions in spite of the fact that 27 patients had laminectomies and 15 had surgical fusions (fig. I).

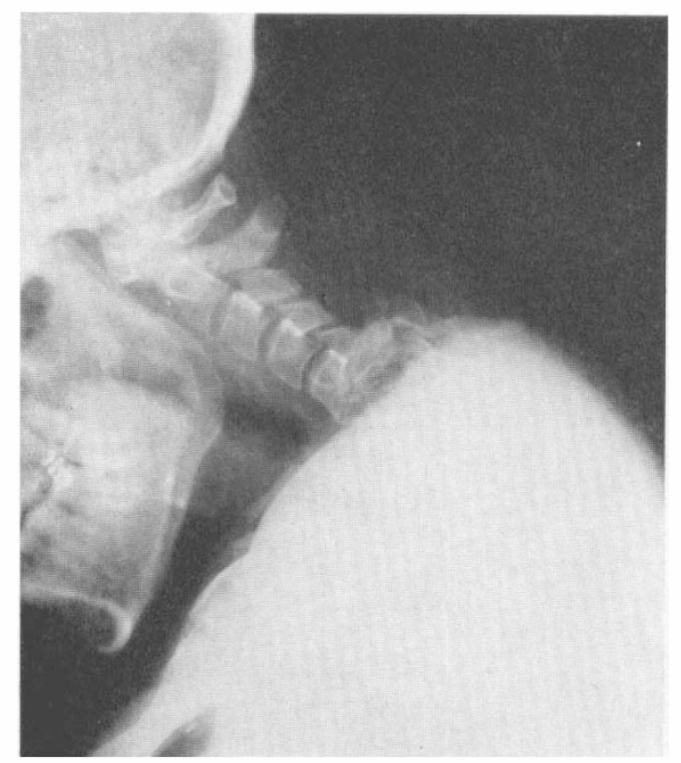

FIG. I

We were unable to confirm or deny the views expressed that early stabilisation improved the likelihood of neurological sparing or recovery. Nevertheless, we accept the opinion that early stabilisation is desirable because it allows early and progressive rehabilitation. Sixty-eight per cent. of the patients having laminectomies required stabilisation procedures immediately or at some time during the course of their rehabilitation.

\section{CASE REPORTS}

The following case histories illustrate and emphasise some of the consequences of laminectomy.

Case I (fig. 2). E. G., a 37-year-old white male, suffered a fracture of $\mathrm{LI}_{\mathrm{I}}$ in a fall. His injury originally resulted in paresthesias only below the level of LI. The patient was continent of bowel and bladder. Two days after his admission to the hospital he was treated with a laminectomy of $\mathrm{T}_{12}$, LI, 2, and 3. Post-operatively, the patient had complete loss of both sensory and motor function below the Tio level. No return of neurological function occurred during a two-year period of post-operative follow-up.

Case 2 (fig. 3). G. P., a 50-year-old white male, suffered a compression fracture of LI when struck by a falling object. Original examination showed only weakness and paresthesias of the lower extremities. Sixteen days after the injury, a laminectomy of TI2 and LI was performed. Post-operatively, the patient was unable to move his legs and had complete loss of neurological function from the level of LI. A post-operative 


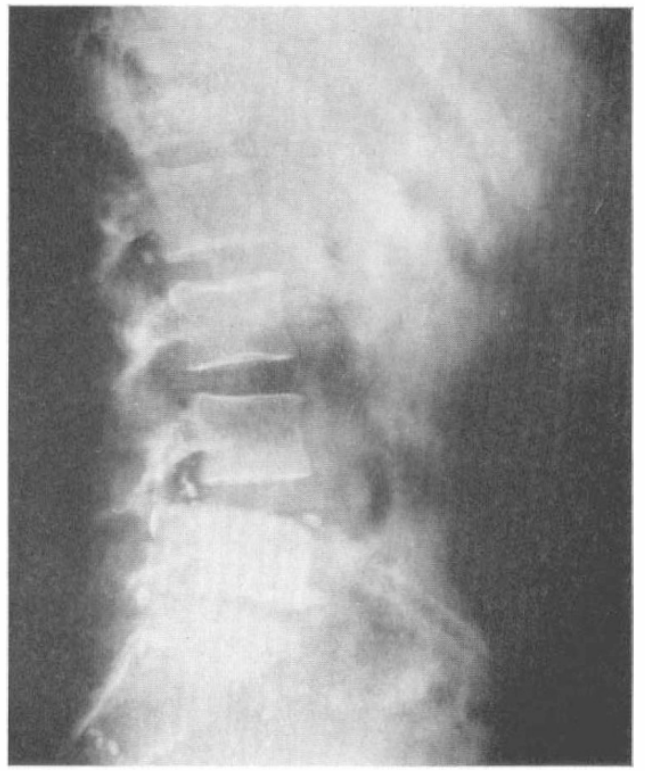

FIG. 2

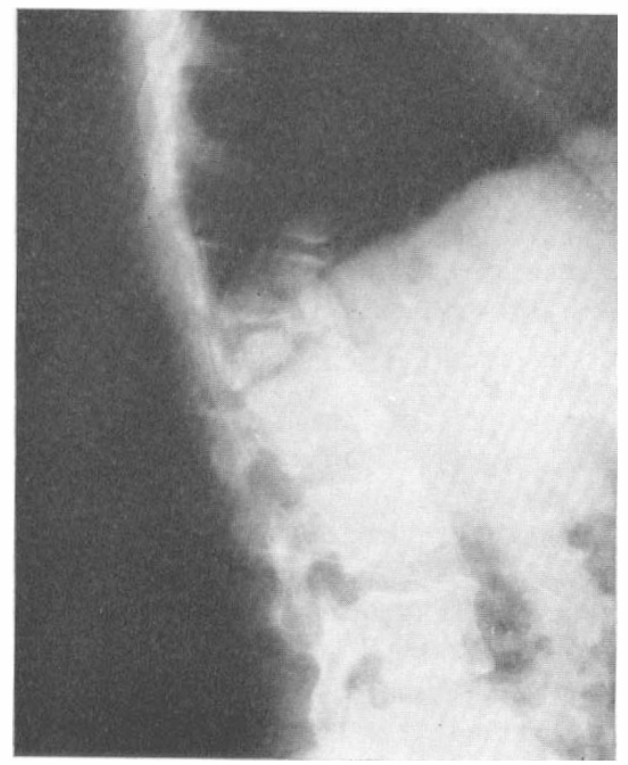

FIG. 3 
wound infection required multiple surgical procedures, and two years and four operations later, no return of neurological function had occurred.

Case 3 (fig. 4). M. D., a 57-year-old Negro female, entered the hospital after a fall down the stairs. Neurological examination revealed mild weakness of the arms and legs with intact sensation. Radiological examination revealed no fracture or dislocation

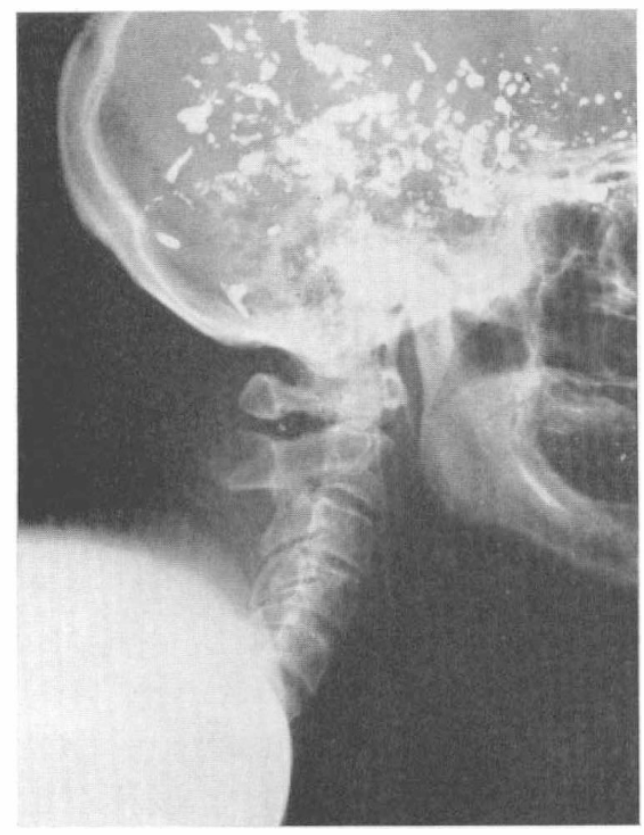

FIG. 4

but cervical spondylosis was present. The patient had a cervical laminectomy from $\mathrm{C}_{3}$ through $\mathrm{C}_{5}$ on the day following her admission to the hospital and post-operatively the patient had a complete quadriplegia at the level of C6. She had no return of function two years later.

\section{DISCUSSION}

The authors acknowledge that the statistics derived from this study cannot be applied to all laminectomies performed for incomplete spinal cord lesions. It is evident that this study was made on patients in a chronic rehabilitation centre and that other patients who make a rapid or complete recovery in an acute hospital will never be admitted to a rehabilitation hospital. Those converted from incomplete lesions to complete lesions, in almost every case will be admitted to a rehabilitation facility. Nevertheless, from this study, it is apparent that the procedure of laminectomy may cause further severe and irreversible damage to the spinal cord.

\section{CONCLUSIONS}

We have concluded that there are few indications for laminectomy which are truly justified when the grave risks are considered. The debridement of a 
compound wound or the open reduction of an irreducible fracture-dislocation may be necessary but laminectomy, performed routinely as an exploratory or diagnostic procedure, cannot be justified in the patient with traumatic spinal cord injury.

\title{
REFERENCES
}

Benassy, J., Blanchard, J. \& Lecog, P. (1967). Neurological recovery rate in para- and tetraplegia. Paraplegia, 4 (February), 259-263.

CAREY, P. D. (I965). Neurosurgery and paraplegia. Rehabilitation (January-March), 27-29.

ClowARD, R. B. (1963). Lesions of the intervertebral discs and their treatment by interbody fusion methods. The painful disc. Clinical Orthopaedics, 27, 5I-77.

GutTMANN, L. (1949). Surgical aspects of the treatment of traumatic paraplegia. The Fournal of Bone and foint Surgery, 31-B, No. 3 (August), 399-403.

HaRRIS, PhIllip (I965-66). The initial treatment of traumatic tetraplegia. Paraplegia, 3, 7I-73.

MUNRO, DONALD (1965-66). The role of fusion or wiring in the treatment of acute traumatic instability of the spine. Paraplegia, 3, 97-III.

TAYlOR, R. G. \& Gleave, J. R. N. (I962). Injuries to the cervical spine. Proceedings of the Royal Society of Medicine, 5, I053.

WALKER, A. EARL (I964). The neurosurgeon's viewpoint. The fournal of Bone and foint Surgery, 46-A, No. 8 (December), I806-I8IO.

White, R. J., Albin, M. S., Harris, L. S. \& Yashon, D. (I969). Spinal cord injury: sequestial morphology and hypothermic stabilization. Surgical Forum, ro (October), 432-434.

\section{STABILITY OF SPINAL FRACTURES AND FRACTURE DISLOCATIONS}

\author{
By G. M. BeDBRook, M.S., F.R.C.S., F.R.A.C.S. \\ Department of Paraplegia, Royal Perth Hospital, Perth, Western Australia
}

IN I 793 discussion on the stability of spinal fracture dislocations was first mentioned by Sommering. The use of laminectomy as a method of management of spinal fractures and fracture dislocations has been argued ever since. Historically, it has been fairly severely dealt with, and yet the argument continues even into I970. The problem of stability has still not been solved.

For a period of 15 years in Western Australia, a neuropathological study has been undertaken of all cases coming to post-mortem, and the few cases who have been submitted to surgical exploration. What do we mean by stability of spinal fracture dislocations? The definition of the word is simple, but as discussed by a number of authorities, it probably means very different things to different people. 'Stability' means to be stable, to be secure, to be inviolate; whilst 'instability' surely means to be insecure or to have a fear of the unknown. The present author believes that we are no longer in the latter category. We no longer should have any fear of the unknown; we now know the pathological problems of stability and this is a subject that can now be practically discussed.

Neuropathology teaches us a great deal about what happens in the spinal column of patients who have sustained fracture dislocations of either the cervicodorsal junction or the lumbo-dorsal junction. In considering the concept of stability of such fractures, I believe that we have omitted a most important aspect 